\section{POETISAS PALESTINAS EN EL EXILIO}

PALESTINIAN POETESSES IN EXILE

Clara M ${ }^{\underline{a}}$ Thomas de Antonio Universidad de Sevilla

\section{Resumen:}

Abstract:

Este trabajo se centrará en la voz de la mujer palestina en el exilio, que ha renovado la voz de las palestinas que vivieron $y / o$ viven en Palestina. En el terreno literario, estas
mujeres destacan sobre todo en el campo de la poesía. Su obra, que no se puede desligar de la geografía y de la historia, está marcada por la tragedia de su pueblo. Además, sus poemas traslucen rasgos característicos de su autoría femenina: están teñidos de anhelo de vida, de fecundidad y de esperanza en el futuro de Palestina. Y, sobre todo, son -como los de tantos poetas palestinos- un poderoso instrumento de resistencia a la ocupación israelí.

\section{Palabras claves:} palestino, literatura femenina árabe.
En ocasiones anteriores nuestra participación en algunos congresos de AUDEM se centró en las poetisas palestinas que residían y componían sus versos en Palestina, especialmente en Fadwa Tuqán, símbolo de la resistencia palestina (Thomas, 2003, 2004 y 2008). Pero muchas otras palestinas, críticas con la ocupación de su patria, se vieron obligadas a exiliarse, a vivir fuera de su tierra y a buscar refugio en otros países. Unas vivieron un tiempo en Palestina antes de marcharse-son las llamadas "de primera generación"-, y otras son hijas de exiliados palestinos -las llamadas "de segunda o tercera generación"-, cuyos poemas se han difundido ampliamente por los nuevos medios de comunicación, generalmente en otros idiomas. Pero, dondequiera que se establecieron, no olvidaron la desgracia de su patria. Por ello su obra refleja, además de los avatares de su país de residencia o del país de sus progenitores, sus sentimientos por la Palestina ocupada y los deseos de un futuro mejor para su pueblo. Entre las poetisas de primera generación destaca Salma Jadra al-Yayyusi (n. 1918), investigadora, profesora y poetisa de origen palestino-libanés, afincada en EEUU tras viajar por diversos países como esposa de un diplomático jordano. Sus obras en prosa o verso reflejan la tragedia de Palestina, pero dejó de escribir poesía tras la Guerra de Junio de 1967, para dedicarse a la divulgación científica de la literatura árabe. En unos poemas evoca a los refugiados de su propia familia, desposeídos de lo suyo por la ocupación, como refleja al inicio de "Sin raíces":

El timbre restalló alto y alarmante.

Luego, esa voz persistente y triste:

"Manda tu ayuda hacia Oriente,

que todos tus tíos se han convertido en refugiados".

Lancé un hondo suspiro, muy angustiada por ellos.

Luego envié a mis tíos ropas

que había apilado para los mendigos,

pasas que había comprado y no comeríamos

pegajosas piastras sin tintineo ni brillo,

lágrimas, lágrimas, lágrimas y un gemido.

Desde ese día no doy mis piastras a ningún mendigo,

porque se han convertido en refugiados mis primos (Boullata, 1982: 131).

En "Elegía a los mártires" muestra a un tiempo la tristeza por quienes dieron su vida por Palestina y el orgullo por su generosidad, pidiendo a su hermosa tierra que los recuerde; en "Tras la marea" se duele del desastre de Palestina; y en "El 5 de junio de 1968" explica cómo ella murió para la poesía tras el desastre de la guerra de 1967:

El pasado Junio rompió la última vena en mi corazón.

¿Has oído algo acerca de mi muerte?

¿Algo acerca de mi desconcertante funeral?

La farsa es que los muertos son anunciados

mientras sufren en la calle, sepultados!

¡Desearía que el ataúd pudiera desaparecer

como los sueños de juventud!

¿Has oído algo acerca de mi muerte?

¿De esa copa de víboras, 
de esa muerte en amor con la muerte?

Sí, lo has oído:

tu enterrador me vio enterrada

cuando ellos le pusieron a mi lado (Jayyusi, 1992: 187).

Entre las obras de Sulafa Hiyyawi (n. 1936), palestina de Nablus exiliada en Iraq donde se licencia, destaca Canciones palestinas, en cuyos versos se dirige al pueblo palestino y a la humanidad. En "A un fida'í" critica a los que no participan en la resistencia, sea dentro o fuera de Palestina, frente a su elogio al fedayín, con el que hasta la propia tierra se siente cómplice; en "El retorno" señala que, cuando se produzca el ansiado regreso a Palestina tras el largo exilio, hallarán la tierra cubierta de sangre, el precio pagado durante la lucha de resistencia; y el poema "El viejo y la tierra" es un diálogo con su tierra palestina de un anciano cuyos hijos luchan por la patria, y al morir en ella serán simiente de futuro:

En los caminos de nuestra aldea,

entre sus olivos tiernos,

le dice el viejo a la tierra:

"Te consagré diez muchachos queridos.

No suspires,

no llores,

los consagré a la Patria..."

Caminan los diez seres queridos en la oscuridad,

los oculta la marcha de una nube,

palpita la tierra en su corazón prendado

para besar sus pasos,

amortigua la sombra sus impacientes suspiros.

En los caminos de nuestra aldea

junto a al-Lidda y ar-Ramla,

allí regresaron nueve;

habían terminado su marcha.

"Pero, ¿y vuestro décimo hermano?"

pregunta el viejo, mientras la luna entristecida

contemplando, permanece en vela.

"Allí lo sembramos, padre.

Allí lo sembramos" (Trad. de Ingrid Bejarano, en Hiyyawi, 1998: 43-44).

Entre las poetisas de segunda generación destaca la americana Farrah Sarafa (s. d), hija de madre palestina y padre iraquí, cuya poesía es una respuesta a la guerra y la ocupación. Poetisa, profesora, editora y traductora, está asentada en Maniatan. Aunque varios de sus poemas se centran en la guerra de Iraq, en “Padre iraquí, Madre palestina" se queja de esa guerra y de la ocupación de Palestina, que le impiden ver a su abuelo iraquí y a su abuela palestina; en "Olivo" su padre saborea el aceite de sus tostadas mientras sueña con el abuelo, con los niños de su país, con los olivos plantados por sus ancestros, con las antiguas canciones, que estarán bajo la radioactividad de las bombas; en "Higo palestino" evoca el sabor de ese manjar que endulzan las penalidades de sus gentes; al inicio del poema "Sólo habla el miedo", referido al ataque contra Iraq, surge la alusión a los israelíes en Palestina:
Siento los gritos de su madre moverse dentro de mi,

mientras quita de la encimera de granito

los jarrones de flores y los potes de mármol.

Tiemblo. Firme la voluntad

y deseando quedarme, estoy hecha de cristal

mientras ese pequeño está hecho de arcilla.

Los soldados americanos le han dado ese pote,

del que los israelíes pueden beber su leche de pasas

en la Palestina de mi madre.

(http://www.warpoetry.co.uk/poemsJLY_06.htm; trad. de C. Ma Thomas).

y en "Colonizando recetas" expresa que, por más que los israelíes que se apropien de las recetas de Palestina para sentir que pertenecen a algo hermoso, no podrán robarles sus señas de identidad:

"Nosotros inventamos esta comida", dice él, cogiendo su hummus,

su tabuleh y su berenjena asada.

"Vosotros la ocupasteis", replica ella.

"Okey, la robamos y entonces la mejoramos, ¿qué te parece? Salam ala lekum".

"Podéis tomar la tierra, pero no nuestra identidad",

canta ella suavemente, cogiendo el bolso para irse.

$\mathrm{Y}$ ahora un poema:

Invadiendo el cuerpo de los pensamientos de nuestro abuelo

con sus cañones hechos en América, contiene el aliento,

incapaz de librarse del azote de dolor que en él traspira

y que en sueños se convierte en lluvia de los ojos de los niños refugiados,

que tejen nuevas artimañas a cambio de dinero para comer,

para tratar de llenar su estómagos vacíos

con el grano que ellos plantaron en Cirjordania

y con el que moldearon recetas de pasta.

Las tías pasan días preparando para la familia

deliciosos bocados para comer,

ahora reemplazados por el hambre y las súplicas

para comer una vez más de las palmas de su madre tierra

para untar sus secos corazones

una vez más con el aceite de oliva

de la fértil Palestina, arrancado de sus entrañas

como una alfombra árabe bordada.

Añoran abrazar los árboles que proporcionaban

aire a los pulmones que respiraban con amor

e imaginaban los ecos mediterráneos

del pasado y las modernas fragancias,

degustadas y deseadas por los extranjeros judíos

ansiosos de sentir que pertenecen

a un lugar hermoso.

Lo adoptan como suyo, cambiando nombres,

jugando a enredar, para apropiarse

de los delicados y aromáticos sabores

de generaciones de palestinos.

Pueblos ocupados, os morís de hambre o coméis

el alimento sembrado en el corazón de mi abuelo

donde el aire palpita puro y verdadero.

(http://www.warpoetry.co.uk/poemsJLY_06.htm; trad. de C. Mª Thomas). 
Náhida Izzat (n. 1960), musulmana de Jerusalén exiliada a partir de la guerra de junio de 1967, es matemática de profesión y aficionada al arte y los trabajos manuales. Comenzó a escribir, animada por sus amistades, sobre sus sentimientos acerca de la patria; pero en su poema “iMírame!” se lamenta de no poder escribir o hacer lo que le gustaría por la violencia que invade su tierra:

¡Mírame!

Quisiera escribir poesía de amor,

pintar arcoiris y mariposas,

oler el aroma de rosas capullos de rosas

y bailar,

bailar con la melodía de jubilosos pájaros azules.

Me gustaría cerrar los ojos y ver a niños sonriendo,

no armas apuntando a sus cabezas,

contarles historias de hadas como lirios en lejanas tierras,

no balas gritando...ni misiles explotando.

Pero,

¿puedo?

Hay un puñal en mi corazón.

Estoy herida,

herida.

Sangro

Tiemblo

Grito.

(http://www.thepeoplesvoice.org/cgi-bin/blogs/voices.php/2008/01/26/p22834; trad. de C. $\mathrm{M}^{\mathrm{a}}$ Thomas)

En "Dimensiones ocultas" describe la vida del pueblo palestino como un tapiz que sólo se puede ver bien con perspectiva, mirando hacia atrás para recordar la masacre de Dayr Yasin, que tiñe sus alegrías de tristeza, y viendo la trayectoria de sus gentes, que tiñe de esperanza sus penas:
Mi primer hijo, Hasan,
nació el 9 de ab
Puedes pensar
tal vez... por qué lo digo
con un tono tan sombrío.
¿Qué hay de malo en el 9 de abril?
Tienes que ser palestino
para comprenderlo,
pues el 9 de abril de 1948

tuvo lugar

a masacre de Dayr Yasin

donde los hombres, mujeres y niños

de esa aldea agrícola pacífica

fueron asesinados a sangre fría.

Nadie sobrevivió

salvo aquellos

que fingieron estar muertos.

Cuando celebramos con alegría

el nacimiento de un recién nacido

nos lamentamos y apenamos

por los amados perdidos.

En nuestro medio

nada está ya aislado,

nada está ya desunido,

no hay colores sencillos.

El tejido de nuestras vidas

forma el más asombroso tapiz.

Si lorma el más asomb́

mirando el lado equivocado

verás reflejada la imagen

sombría de un borroso retrato,

con pliegues... nudos e hilos raídos.

Si le das la vuelta

parece más claro.

Pero aún no puedes verel retrato completo,

sólo colores y sombras

Pero, joye!... ¡ tómate un ratito

y camina hacia atrás,

Miro más atrás!

¡Mira el tap

de lejos!

Entonces te asombrarás

de su inmensa belleza,

de todas esas lóbregas sombras

que no te hicieron sentir,

que ni siquiera te perturbaron

cuando estabas cerca.

Desde lejos

esas oscuras sombras

son precisamente las que hacen esta pieza

tan singular,

tan espectacular.

Esos matices insondables

son los que dan su profundidad

y dimensiones ocultas

al retrato de nuestra vida.

Desde ese día de 1948,

muchos... muchos niños nacieron

el 9 de abril.

Nuestras alegrías siempre están teñidas

por toques de pena.

Nuestra tristeza siempre está coloreada 
por matices de esperanza.

Sin ello,

el tapiz de nuestras vidas

nunca estaría completo,

ni sería tan rico

ni tan hermoso.

No pierdas mucho tiempo

Mirando rabioso el lado equivocado!

¡Dirando rabioso el lado equivocado!

voices.php/2008/01/26/p22834; $\quad$ trad. $\quad$ de $\quad$ C.

Thomas).

En "Querido pueblo de Gaza" invita a quienes piensan angustiados en cómo ayudar a los palestinos a comportarse con la misma valentía que ellos:

¡Atesorado pueblo de Palestina,

maestro de coraje y dignidad

Permíteme arrodillarme

lavar tus pies con mis lágrimas,

besar tus benditas manos

y rociar tus hermosos rostros con almizcle y rosas!

Mientras nosotros nos sentamos meditando como locos,

totalmente desesperados,

hablando mucho y haciendo menos,

dando vueltas en circulo

qué ofrecer para aliviar en algo tu sufrimiento,

vienes, como de costumbre

lleno de sorpresas, en nuestro rescate, para suavizar nuestra agonía

Te nos presentas con los más preciosos regalos,

lecciones de heroísmo, firmeza,

paciencia, perseverancia, desafío, resiliencia,

optimismo contra toda disputa,

.

Habéis demostrado que vosotros sois los libres... y nosotros los cautivos.

i siquier por los más poderosos.

¿Nunca aprenderemos la lección?

(http://www.thepeoplesvoice.org/cgi-bin/blogs/voices.php/2008/01/26/p22834; trad. de C. Mª Thomas)

En “Creo en los milagros” confronta el aparente poder de Israel para oprimir a los palestinos con la verdadera fuerza, voluntad y fe de este pueblo:

Puedes quebrar mis huesos.

Mi espíritu libre es invencible.

Puedes dejarme ciego.

La luz de mi intuición

nunca podrás apagarla.

En las sombras de la tiniebla

yace el cadáver de tu poder.

Puedes destruir mi casa.

La ventana de mi esperanza

nunca podrás romperla.

Los pilares de mi fenunca podrás hacerlos temblar.

Puedes amenazarme

con armas de muerte y destrucción masiva,metiéndome el miedo en el corazón

Pero no puedes lograr

o puedes cortar

mi divina conexión.

Con un misil

puedes destrozar mi cuerpo.

Sin embargo, mi alma

está fuera de tu alcance,

intacta para siempre.

¡Tú cantaste victoria en seis días

Victoriosos son los que,

mirando con dignidad,

e enfrentan a los tanques con su carne fresca

y, sólo con piedras,

al fuego de los cazas F-16.

Nunca podrás derrotar mi voluntad,

porque mi poder, que no te puedes explicar,

crece de las raíces de mi pena.

Tú dependes de Estados Unidos

para los suministros y la riqueza.

Manda mi infinita fuerza

del más grande, mi Creador.

(http://www.thepeoplesvoice.org/cgi-bin/blogs/voices.php/2008/01/26/p22834;

trad. de C. MThomas).

Uno de sus poemas más conmovedores es "Quiero contarle al mundo", que aparece en la red acompañado de imágenes de niños, jóvenes y adultos palestinos en diversas escenas en las que se muestra aquello que no fue posible hacer o que se destruyó en Palestina; y al final la poetisa invita al mundo a encender velas para que se desvanezca tanta oscuridad:

Quiero contarle al mundo un cuento

... sobre un hogar con una linterna rota..

...y una muñeca quemada...

...sobre un día de campo que nadie disfrutó...

...sobre un hacha que mató un tulipán..

...sobre un fuego que consumió una trenza...

..un cuento sobre una lágrima que ya no pudo derramarse..

Quiero contar un cuento sobre una cabra que ya no fue ordeñada..

...sobre una masa que ya no fue horneada..

...sobre una boda que no se celebró..

..y una pequeña que no pudo crecer..

...sobre un balón que no fue pateado...

...sobre una paloma que no voló...

Quiero contarte un cuento sobre una llave que no fue usada..

...sobre un aula de clases a la que no se acudió...

...sobre un patio de recreo que fue silenciado...

...sobre un libro que no fue leído..

...sobre una solitaria granja sitiada y sobre sus frutos que nadie recogió...

...sobre una mentira que no se descubrió..

...un cuento sobre una iglesia en la que ya no se reza.

...y una mezquita que ya no está en pie...

...y una cultura de la que ya no se disfruta.. 
Quiero contar un cuento sobre un techo con hierba y lodo..

...sobre una piedra que se enfrentó a un tanque...

...y sobre una empecinada bandera que se niega a ser arriada...

...sobre un espíritu que no puede ser derrotado...

...quiero contarle al mundo un cuento.

Ahora, encendamos una velita por Palestina.

Puedes hacerlo

Enciende una velita

Mira cómo se desvanece la oscuridad.

Sólo inténtalo.

Un rayo de luz

barre lo más triste,

noches de azabache

hasta que rompe el alba

Sólo observa

¿Puedes ver que

todo el poder de la oscuridad

en el mundo

no puede extinguir

el más exánime parpadeo

de un haz de luz?

Enciende una vela.

Una velita.

Mira como se desvanece la oscuridad.

Puedes hacerlo.

Oye, MUNDO

¿Me escuchaste?

(www.tlaxcala.es/asp?reference=9556\&lg=es; trad. de Yaotl Áltan).

Ante esta situación no puedes menos que gritar: “Humanidad, ¿dónde estás?”

reprochando al mundo su ceguera y sordera mientras su pueblo muere en Gaza:

Me están estrangulando

bajo tus vigilantes ojos.

Tengo frío...frío...frío.

Tiemblo.

Grito.

Humanidad, ¿dónde estás?

¿Por qué vuelves el rostro?

¿Por qué muelves el rostro?

Estoy aquí,

languideciendo

en los pasadizos de Gaza.

Humanidad, ¿dónde estás?

¡Mírame"

¡Repara en mí!

Estoy aquí,

suspirando

en los pasadizos de Gaza.

Tiemblo.

Grito.

¡Humanidad

deja de mirar para otro lado,

de volverte sorda de volverte ciega,

mientras yo

$\mathrm{y}$, oh, mis pobres niños

morimos!

(http://www.thepeoplesvoice.org/cgi-bin/blogs/voices.php/2008/01/26/p22834;

trad de C. MaThomas.

Suheir Haddad (n. 1973), escritora, activista y actriz de origen jordano-palestino instalada en el Brookling neoyorquino y luego en Staten Island, rechaza en su poemas cualquier violencia, como hace en “Lo que yo quiero", poema a favor de la vida y contra la guerra; en otra ocasión, horrorizada por los ataques a la Torres Gemelas en 2001, escribió el largo "Poema sobre crisis y terror" reviviendo todos los acontecimientos de esta tragedia y haciendo diversas referencias a su identidad palestina, sin hallar diferencias entre distintos pueblos, razas o religiones que puedan justificar esa masacre, así como a su temor a las posibles represalias contra los árabes o palestinos tras las reacciones que se produjeron entre algunos americanos. $Y$ en otros denuncia todas las lacras y violencias, en especial las de Palestina, como dice al final de "Ruptura en racimo":

¿Adónde van los corazones de los refugiados?

Rotos, insultados, colocados en un lugar de donde no son,

no quieren que no se les vea.

Enfrentados a la ausencia,

lloramos al otro o no significamos nada.

Mi espina se curva en espiral.

El precipicio corre hacia y desde los seres humanos.

Dejamos atrás bombas de racimo.

Minas de facto.
Dolor en llamas.

Cosecha de tabaco contaminado.

Cosecha de bombas.

Cosecha de dientes de leche.

Cosecha de palmas, humo.

Cosecha de testigos, humo.

Resoluciones, hum

Salvacion, humo.

Redención, humo.

Respira.

No temas

a lo que ha estallado.

Si has de hacerlo,

teme a lo que aún no ha explotado.

(http://www.ted.com/speakers/suheir_hammad.html; trad. de Laura Casielles).

Por último hay que destacar a Rafeef Ziadah (s.d.), poetisa, periodista, profesora y activista palestina refugiada en Canadá, y una de las más difundidas por los medios. Uno de sus poemas más conocido es "Tonalidades de la ira", escrito durante los bombardeos sobre Gaza (diciembre 2008-enero 2009) por el ejército de Israel, mientras los niños morían bajo las bombas de fósforo lanzadas por los aviones de los israelíes, 
aliados de Occidente y ocupantes de Palestina, que aplican a los palestinos con mano de hierro un régimen de apartheid que deja pequeño al que sufrieron los sudafricanos hasta 1994:

Escribí este poema cuando estábamos haciendo

una acción directa en mi Universidad. (...)

Estaba sentada en el suelo, cuando ese mamarracho

vino y me dio una patada en la tripa diciendo:

"Merecerías que te violasen antes de tener hijos terroristas".

Entonces no dije nada, sino que escribí este poema

para ese señorito":

¡Permíteme que hable en mi legua árabe

antes de que también ocupen mi lengua!

¡Permíteme que hable en mi legua materna

antes de que también colonicen

yoy una mujer arabe de color,

Todo lo que mi abuelo quería era

Todo lo que mi abuelo quería era

despertarse al alba y ver a mi abuela rezar de
en una aldea escondida entra Yaffa y Haifa.

Mi madre nació bajo un olivo,

en una tierra que, como dicen, ya no es mía.

Pero yo atravesaré sus barreras, sus puestos de control,

sus malditos muros de apartheid, y retornaré a mi patria.

Soy una mujer árabe de color, y venimos de todas las tonalidades de la ira.

Tú has oído ayer gritar a mi hermana

al dar a luz en uno de sus puestos de control,

con soldados israelíes buscando entre sus piernas

a su próxima amenaza demográfica,

su hijita llamada Yanín

Tú has oído gritar a Amni Mona

tras los barrotes de su prisión mientras gaseaban su celda:

"Estamos volviendo a Palestina!".

Soy una mujer árabe de color, y venimos de todas las tonalidades de la ira.

Pero tu me dices que este útero que hay en mi interior

sólo te traerá tu próximo terrorista,

usando barba y blandiendo una pistola, con turbante, y negro como la arena.

Tú me dices que mando a mis hijos a morir,

Pero son vuestros helicópteros y F-16 los que están en nuestro cielo.

¡Vamos a hablar sobre el asunto del terrorismo un segundo!

¿No fue la CIA la que mató a Allende y Lumumba

y quien primero adiestró a Osama?No fueron mis abuelos quienes corrían como

payasos,

con capas y capuchas blancas en la

cabeza, linchando a los negros.

Soy una mujer árabe de color, y venimos de todas las tonalidades de la ira.

“Quién es esa mujer morena gritando en la manifestación?".

¡Perdón! ¿Es que yo no debería gritar?

He olvidado ser tu siempre orientalista sueño, genio en una botella

bailarina del vientre, joven de harén, mujer árabe de voz suave

que dice: Sí, señor, no señor.

-Gracias por los sándwiches de manteca de cacahuete

que deja caer sobre nosotros tu dueño de los F-16!
Sí, mis libertadores están aquí para matar a mis hijos,

y llamarles "daños colaterales".

Soy una mujer árabe de color, y venimos de todas las tonalidades de la ira.

¡Así que déjame decirte que este útero que hay en mi interior

sólo os traerá un próximo rebelde.

Tendrá una piedra en una mano y una bandera palestina en la otra.

Tendra una piedra en una man y

¡Cuidado $i$ iCuidado con mi ira...!

(http://www.universalsubtitles.org/es/videos/W20kz7C8G9dU/en/231466/; trad.

de C. M ${ }^{\mathrm{a}}$ Thomas).

Pero quizás su poema más famoso sea "Nosotros enseñamos vida, señor", también escrito durante el bombardeo de Gaza en respuesta a un periodista que le preguntó “¿No crees que todo estaría bien si simplemente dejarais de enseñar a vuestros hijos a no odiar?":

Hoy, mi cuerpo fue una masacre televisada.

Hoy, mi cuerpo fue una masacre televisada

que tenía que caber en audio digital y en palabras limitadas.

Hoy, mi cuerpo fue masacre televisada que tenía que caber

en un audio digital y palabras limitadas, con suficientes estadísticas

como para contrarrestar una respuesta mesurada.

Yo había perfeccionado mi inglés y aprendido las resoluciones de la ONU.

Pero, aun así, me preguntó.

"Señorita Ziadah, ¿no cree que todo se resolvería si dejaran

de enseñar tanto odio a sus hijos?"

Pausa.

Miro en mi interior.

Busco fortaleza para tener paciencia,

pero no tengo paciencia en la punta de la lengua

mientras caen bombas sobre Gaza.

La paciencia me ha abandonado.

Pausa.

Sonrisa.

"Nosotros enseñamos vida, señor".

(Rafeef, acuérdate de sonreír).

Pausa.

"Nosotros enseñamos vida, señor"

Nosotros los palestinos

enseñamos vida después de que ellos

hayan ocupado los últimos qielos.

Nosotros enseñamos vida despr

作

hayan construido sus asentamientos y muros de apartheid más allá

de los últimos cielos.

Nosotros enseñamos vida, señor.

Pero hoy, mi cuerpo fue una masacre televisad

para caber en un audio digital y palabras limitadas.

Danos sólo un reportaje, un reportaje con lado humano.

Verás, esto no es político.

Sólo queremos hablarle a la gente

de ti y de tu pueblo,

así que danos un reportaje humano. 
No menciones las palabras

"apartheid"

y "ocupación".

Esto no es político.

Me tienes que ayudar

como reportera

a ayudarte a contar tu historia,

que no es un reportaje político.

Hoy, mi cuerpo fue una masacre televisada.

¿Y quétal si me das un reportaje

sobre una mujer en Gaza que necesita medicinas?

¿Qué tal acerca de ti?

¿Tienes suficientes huesos rotos en las extremidades

como para cubrir el sol?

Pásame tus muertos y dame una lista

de sus nombres

en un total de mil doscientas palabras.

Hoy, mi cuerpo fue una masacre televisada

que tenía que caber en un audio digital y palabras limitadas

y conmover a quienes

son insensibles a la sangre

terrorista.

Pero ellos sintieron pena.Sintieron pena por el ganado en Gaza.

Así que les di

resoluciones de la ONU

y estadísticas

y condenamos

y deploramos

y rechazamos.

Y no son iguales

ocupadores y ocupados.

$Y$ cien muertos, doscientos muertos, y mil muertos.

$Y$ entre eso,

entre crimen de guerra y masacre,

ventilé las palabras y sonreí,

-no exótica-

-no terrorista-

Y cuento:

Cuento cien muertos, doscientos muertos, mil muertos.

¿Hay alguien ahí?

¿Hay alguien ahi?

cuchará alguien?

Quisiera poder llorar sobre sus cadáveres.Quisiera simplemente

correr descalz

por cada campo de refugiado

y abrazar a cada niño;

cubrir sus oídos

para que no escuchen el sonido

de las bombas

por el resto de sus vidas,

como yo lo escucho..

Hoy, mi cuerpo fue una masacre televisada.

Y déjame decirte:

No hay nada que tus resoluciones de la ONU hayan hecho en absoluto sobre esto.

$Y$ no hay un audio digital,

-ningún audio digital que se me ocurra

y no importa cuán bueno sea mi inglés-

no hay audio digital

no hay audio digital

o hay audio digita

hay audio digital

no hay audio digital

que los devuelva a la vida.

No hay audio digital que arregle esto.

Nosotros enseñamos vida, señor.

Nosotros enseñamos vida, señor.

Nosotros

los palestinos

nos levantamos

cada mañana

para enseñar

al resto del mundo

vida

(http://apologadelaluz-jorgeespina.blogspot.com.es/2012/01/rafeef-ziadah-

nosotros-ensenamos-vida.html. Trad.de Patricia Bobillo Rodríguez).

\section{REFERENCIAS BIBLIOGRÁFICAS}

Boullata, I. J., Modern Arab Poets, Heinemann, Londres, 1976.

Hiyyawi, S., Una voz palestina. Introducción, traducción y selección de Ingrid Bejarano. Letrúmero, Madrid, 1998.

Jayyusi, S. K., Anthology of Modern Palestinian Literature, Edición y traducción, Columbia University Press, Nueva York, 1992.

Thomas de Antonio, Cl. Maㅗ “Voces de mujer en Palestina”. Arriaga Flórez, Mercedes (Ed.), Entretejiendo saberes. Actas del V Seminario de la Asociación Universitaria de Estudios de Mujere (AUDEM), (Sevilla, 17 a 19 de octubre de 2002), [CD] Vicerrectorado de Calidad y Nuevas Tecnologías, Universidad de Sevilla, Sevilla, 2003.

----, “Fadwa Tuqán, del harén a la arena palestina”. Arriaga Flórez, Mercedes y otros (Ed.), Los estudios de las mujeres hacia el espacio común europeo, ArCiBel Editores, Sevilla, 2004, 296-319.

----, “En memoria de la poetisa Fadwa Tuqán, símbolo de la resistencia palestina”. Arriaga Flórez, Mercedes y otros (Ed.). De lo sagrado y lo profano. Mujeres tras/ entre/sin fronteras, ArCiBel Editores, Sevilla, 2008, pp. 517-542. 